Article

\title{
Low-Threshold-Voltage and Electrically Switchable Polarization-Selective Scattering Mode Liquid Crystal Light Shutters
}

\author{
Zhe-Yung Liang, Ching-Yen Tu, Tsung-Hsun Yang, Cheng-Kai Liu * and Ko-Ting Cheng *(D) \\ Department of Optics and Photonics, National Central University, 320 Taoyuan, Taiwan; \\ c122388827@gmail.com (Z.-Y.L.); best841217@gmail.com (C.-Y.T.); thyang@dop.ncu.edu.tw (T.-H.Y.) \\ * Correspondence: aerobert007@gmail.com (C.-K.L.); chengkt@dop.ncu.edu.tw (K.-T.C.); Tel: +886-3-4227151 \\ (ext. 25240) (C.-K.L.); Tel: +886-3-4227151 (ext. 65269) (K.-T.C.)
}

Received: 12 October 2018; Accepted: 30 November 2018; Published: 6 December 2018

\begin{abstract}
Low-threshold-voltage $\left(\mathrm{V}_{\mathrm{th}}\right)$ and electrically switchable, polarization-selective scattering mode light shutters (PSMLSs) using polymer-dispersed liquid crystals (PDLCs) are demonstrated in this work. The optimized weight ratio of the nematic liquid crystals (LCs) to the adopted monomer (NBA107, Norland Optics) in the low- $V_{\text {th }}$ PDLCs based on NBA107 is 7:3, [7:3]-PDLCs NBA107.

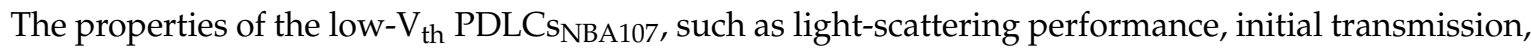
$\mathrm{V}_{\text {th }}$, and droplet size were investigated. Experiment results show that the surface anchoring (threshold-voltage) of NBA107 is weaker (lower) than or equal to that of the common NOA65. The cost is that the response time of the proposed PDLC $s_{\mathrm{NBA} 107}$ is relatively long. A method to reduce the decay time, which can be applied to all other PDLC devices, will be elucidated. In addition to the low $\mathrm{V}_{\text {th }}$ of the proposed PDLCs $\mathrm{SBA}_{\mathrm{NB} 107}$, the operation voltage $\left(\sim 6 \mathrm{~V}_{\mathrm{rms}}\right)$ to approach the maximum transmission is relatively low in a $7 \mu \mathrm{m}$-thick PDLCs $\mathrm{NBA107}$ cell. Moreover, the polarization-selective

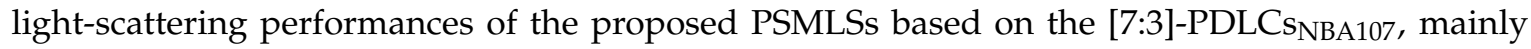
driven by in-plane and vertical fields, are also demonstrated.
\end{abstract}

Keywords: liquid crystals; polarization; scattering; polymers

\section{Introduction}

Optical devices based on polymer-dispersed liquid crystals (PDLCs) have been studied worldwide for several decades because of their electrically switchable light-scattering properties [1,2]. PDLCs can be applied to light shutters, 2D/3D switching, displays, holographic gratings, optical retardations, and so forth [1-12]. Polymers and liquid crystals (LCs) with a proper weight ratio are initially well-mixed with each other, and LC droplets can be formed in a continuous polymer matrix through polymerization-induced phase separation (PIPS) after treatment with UV illumination for a certain duration [1,2]. With regard to the range of the visible wavelength and without the application of an external field, PDLCs scatter unpolarized visible lights because of the random distribution of the LC directors in individual droplets. Visible lights are scattered because they encounter a refractive index mismatch between LC droplets and polymers. The size of LC droplets should be around the wavelength of visible lights, indicating that the diameters of the LC droplets are in the order of approximately $0.2-10 \mu \mathrm{m}[12,13]$. For common PDLCs that apply an external field [1,2], LCs $(\Delta \varepsilon>0)$ in each LC droplet are rotated to be parallel to the field direction. If the refractive index of the adopted polymers is close to the ordinary refractive index $\left(n_{\mathrm{o}}\right)$ of the used LCs, then incident lights do not encounter the refractive index mismatch between LCs and polymers. Accordingly, all visible lights pass through the PDLC cell. The performances of PDLCs which are based on several popular polymers 
produced by Norland Products Inc. (Cranbury, NJ, USA), such as NOA81, NOA68, and NOA65, have been reported in previous studies [1,6,14-18]. By contrast, in this study, PDLCs based on the other polymer of Norland Products Inc., namely, NBA107, are proposed for the first time. This paper reports the full investigation of the NBA107-based PDLCs.

Several methods are reported to decrease the operation voltage in PDLCs. Hsu et al. found that the operation voltage $\left(\mathrm{V}_{\mathrm{op}}\right)$ and threshold voltage $\left(\mathrm{V}_{\mathrm{th}}\right)$ of the PDLCs doped with a suitable weight percentage of $\mathrm{ZnO}$ nanoparticles were reduced [18]. Chan et al. indicated that the silver-coated polystyrene microspheres doped in PDLCs construct an induced electric field to enhance the effective field in PDLCs and reduce $\mathrm{V}_{\mathrm{op}}$ [19]. Additionally, Silva et al. demonstrated the method for modifying the surface anchoring on the interface between LC droplets and polymers by doping specific additives into PDLCs to reduce $\mathrm{V}_{\mathrm{op}}$ [20]. Drevenšek-Olenik et al. reported LC dynamics driven by in-plane electric fields in a holographic PDLC transmission-grating cell [9]. They also reported that optical retardation contributed to PDLC cells driven by in-plane electric fields [10]. Manda et al. also proposed a method to approach the polarization-insensitive PDLC grating, driven by in-plane fields [21]. To obtain interesting optical results, we used three terminal electrodes to demonstrate the optical

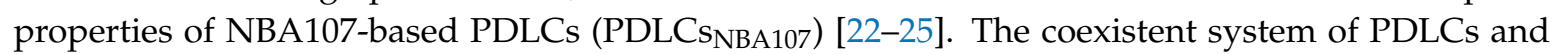
polymer-stabilized LCs are also reported [26]. Recent related studies about novel fabrication of phase-separated LC-polymer composites can also be useful references on developing PDLCs [26-29].

In this study, a low $-\mathrm{V}_{\mathrm{th}}$, low- $\mathrm{V}_{\mathrm{op}}$, and electrically switchable polarization-selective scattering mode light shutter (PSMLS) using PDLCs is demonstrated. The monomer used herein was NBA107,

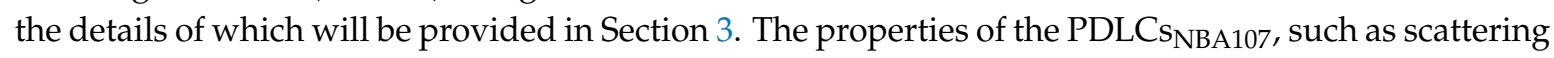
performance, $\mathrm{V}_{\text {th }}$, initial transmission, surface anchoring, and droplet size were investigated in detail and compared with those of the PDLCs based on the popular monomer, NOA65. The weight ratio of the selected materials (LCs: monomer $=7: 3$ ) in PDLCs NBA107 $_{\text {to }}$ approach the low $\mathrm{V}_{\text {th }}$ and the high contrast ratio was optimized experimentally. Experiment results show that the surface anchoring of NBA107 is weaker than or equal to that of NOA65, so the $\mathrm{V}_{\text {th }}$ of the PDLCs $\mathrm{S}_{\mathrm{NBA} 107}$ is relatively low. However, the response time of the proposed PDLC $\mathrm{S}_{\mathrm{NBA} 107}$ is relatively long. A method to reduce the response time which can be applied to all PDLC devices will also be proposed, and the fabrication processes of the PDLCs $s_{\mathrm{NBA} 107}$ are also optimized and discussed. The polarization-selective light-scattering

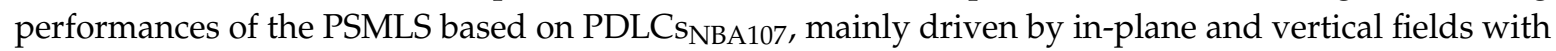
low $\mathrm{V}_{\text {th }}$, are also demonstrated. The PSMLS mainly driven by an in-plane field were found to scatter the incident lights with the polarization direction parallel to the in-plane field direction, whereas the PSMLS driven by a vertical field provided polarization-independent light-scattering performance.

\section{Operation Mechanism of Electrically Switchable PSMLS Using PDLCs}

Figure 1 shows the schematic diagram of the electrode structure of the proposed PSMLS. The width of the electrode stripe and the gap between two adjacent stripes are 8 and $12 \mu \mathrm{m}$, respectively. The bottom substrate is coated with interdigital electrode stripes to produce in-plane electric fields, whose direction is parallel to the $x$-axis. The top substrate is coated with an indium-tin-oxide (ITO) electrode film. By properly selecting the applied electric potentials onto these three electrodes, in-plane and vertical electric fields can be easily generated and applied onto the PDLCs, as shown in Figure 2. Figure 2a presents the configurations of LC directors in LC droplets in the PSMLS, mainly driven by the two bottom interdigital electrodes. To produce in-plane fields, the electric potential on the top ITO electrode film (Figure 1) needs to be an open-circuit potential (floating), whereas the applied electric potentials on the blue and light-yellow interdigital electrode stripes (Figure 1) should be different to produce the required in-plane external fields with suitable voltages. Undesirable vertical fields should also be considered. 


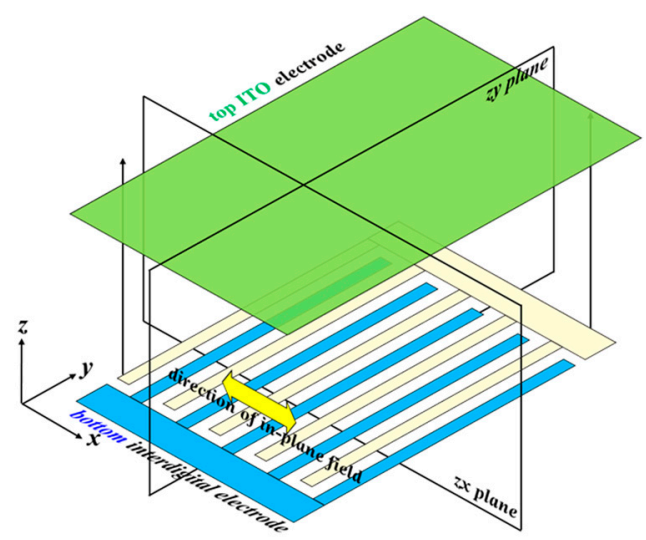

Figure 1. Schematic drawing of the electrode structures of the proposed polarization-selective scattering mode light shutter (PSMLS).

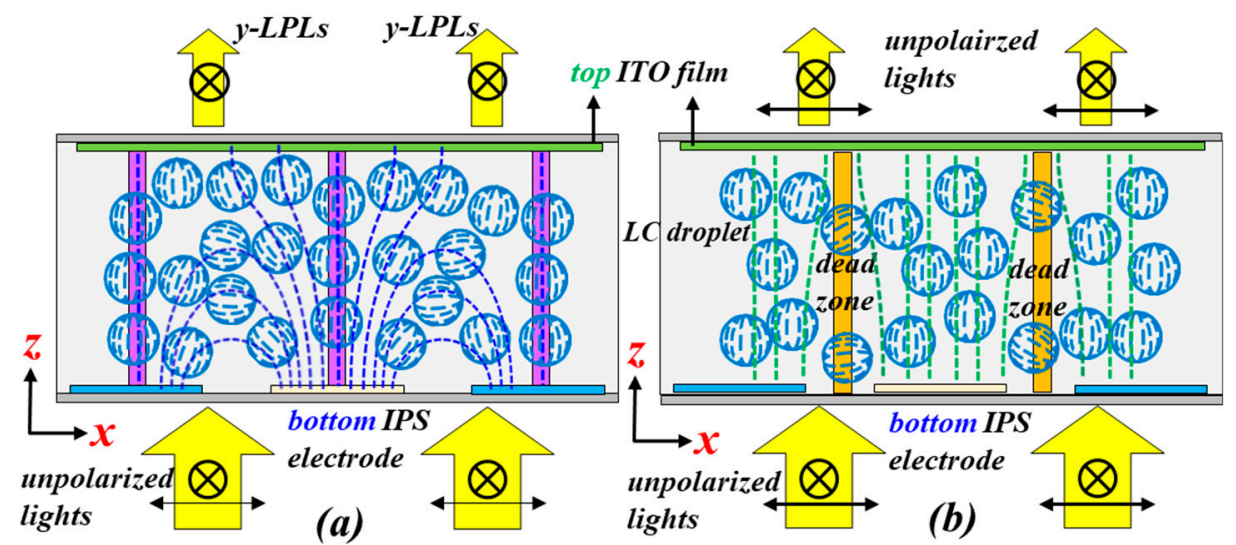

Figure 2. Schematic configurations of light polarization, electric field directions, and liquid crystal (LC) directors in LC droplets in the PSMLS mainly driven by (a) in-plane and (b) vertical electric fields.

With regard to the case shown in Figure 2a, unpolarized lights can be divided into two orthogonal, linearly polarized lights, including the polarization directions parallel to the $\pm \boldsymbol{y}$ - and $\pm \boldsymbol{x}$-axes, denoted by $y$-LPLs and $x$-LPLs, respectively. When suitable electric potentials are applied onto the blue and light-yellow interdigital electrode stripes (Figure 2a), in addition to the refractive index of the polymer, $\mathrm{n}_{\mathrm{p}}$, most of the components of $x$-LPLs encounter various effective refractive indices of LCs $\left(n_{\mathrm{eff}}\right)$, while the components of $y$-LPLs encounter the $\mathrm{n}_{\mathrm{o}}$. This is because most of the effective electric fields between two adjacent interdigital electrodes are not parallel to the $\pm x$-axis. Thus, most of the LCs in the LC droplets rotate in the $x z$-plane with their director projection parallel to $\pm x$-axis. In accordance with the basic requirement of PDLCs, the refractive index of the polymer should be close to the $n_{\mathrm{o}}$ of the adopted LCs [1]. Accordingly, under this condition, incident lights with polarization directions parallel to the effective in-plane electric field direction ( $x$-LPLs) in Figure 2a are scattered because they encounter the largest refractive index mismatch between LCs and polymers [ $\left(n_{\mathrm{eff}} n_{\mathrm{p}}\right)$ or $\left.\left(n_{\mathrm{e}}-n_{\mathrm{p}}\right)\right]$ in the PSMLS, whereas the incident lights with polarization directions perpendicular to the effective in-plane electric field direction ( $y$-LPLs) can pass through the PSMLS because of the absence of a refractive index mismatch, due to the equal $n_{p}$ and $n_{o}[1,2]$. However, in practical application, a small number of LCs in LC droplets close to the purple zones (Figure 2a), which are the central regions of each electrode stripe, rotate to be perpendicular to the substrates via the effective vertical fields (floating) [24,25]. Accordingly, the transmittance of either $x$-LPLs or $y$-LPLs is increased. As to the case with the application of the vertical electric field, Figure $2 b$ shows the detailed configurations of the proposed PSMLS applied with a vertical electric field provided by the bottom interdigital electrode stripes and top ITO electrode film. The electric potentials applied onto the blue and light-yellow interdigital electrode stripes (Figure 1) are the same, but different from that applied to the top ITO 
electrode film. Therefore, the direction of the applied electric fields in most regions is perpendicular to the substrates, i.e., vertical electric fields, but the effective electric fields close to the edges of the electrode stripes are not exactly perpendicular to the substrates. Thus, a small amount of LCs in LC droplets close to the edges of electrode stripes cannot completely rotate to be perpendicular to the substrates [1]. Thus, the transmittance of $x$-LPLs is reduced. Moreover, a small amount of LCs in LC droplets close to the dead zones (orange region in Figure $2 b$ ), which are the areas in the central region between two adjacent electrode stripes, cannot be oriented [1]. Accordingly, this condition also causes a reduction of transmittance of either $x$-LPLs or $y$-LPLs.

\section{Preparation of PDLCs}

The materials used in this study were nematic LCs, E7 (Merck), and monomers, namely, NBA107 and NOA65 (Norland Optics). Mixture A (B) was composed of E7 and NBA107 (E7 and NOA65). Table 1 lists the refractive indices of E7, cured NBA107, and cured NOA65. Table 2 shows the mechanical properties of the adopted monomers of NBA107 and NOA65. The PDLCs produced from mixtures A and B were called PDLC $s_{\mathrm{NBA} 107}$ and PDLC $\mathrm{s}_{\mathrm{NOA} 65}$, respectively. The low shrinkage and low strain are the key characteristics of the adopted monomer NBA107 to minimize the potential strain [14]. Two types of empty cells were prepared. The first type of empty cell, fabricated by assembling two glass substrates coated with ITO films, was used for the experiments in Section 4.1. No alignment processes were used on the top of these two ITO-coated substrates. Empty cells with thicknesses (cell gaps) of $7 \mu \mathrm{m}$, defined by sprayed ball spacers, were filled with the homogeneous mixtures through capillary action. The light transmission of an empty cell was approximately $82 \%$. Then, the PDLCs NBA107 $_{\text {and }}$ PDLC $s_{\text {NOA65 }}$ cells were produced via PIPS through UV illumination for certain optimized durations. The second type of empty cell, fabricated by assembling two glass substrates, was used for the studies in Section 4.2. One substrate was coated with patterned interdigital electrodes, whereas the other was fully coated with an ITO film. The empty cell with a thickness of $7 \mu \mathrm{m}$, defined by ball spacers, was filled with homogeneous mixture A with an optimized ratio by capillary action to complete the PSMLS via PIPS through UV illumination for certain optimized durations. No photo-initiator was used in all PDLC cells. Sections 4.1 and 4.2 provide the detailed conditions of the intensity and duration of the UV illumination processes. The $365 \mathrm{~nm}$ central wavelength of the UV light was used to activate PIPS.

Table 1. Refractive indices of E7, NBA107, and NOA65.

\begin{tabular}{ccc}
\hline E7 & NOA65 & NBA107 \\
\hline Extraordinary (ordinary) & Refractive index & Refractive index \\
refractive index & after polymerization & after polymerization \\
$1.737(1.5185)\left[20^{\circ} \mathrm{C}, \lambda=633 \mathrm{~nm}\right]$ & 1.524 & 1.51 \\
\hline
\end{tabular}

Table 2. Mechanical properties of NBA107 and NOA65.

\begin{tabular}{cccccc}
\hline & Viscosity (25) & $\begin{array}{c}\text { Modulus of } \\
\text { Elasticity (psi) }\end{array}$ & $\begin{array}{c}\text { Tensile } \\
\text { Strength (psi) }\end{array}$ & $\begin{array}{c}\text { Elongation } \\
\text { at Failure }\end{array}$ & $\begin{array}{c}\text { Hardness- } \\
\text { Shore D }\end{array}$ \\
\hline NBA107 & $350 \mathrm{cps}$ & 800 & 78 & $5 \%$ & 15 \\
NOA65 & $1200 \mathrm{cps}$ & 20,000 & 1500 & $80 \%$ & 50 \\
\hline
\end{tabular}

\section{Results and Discussion}

\subsection{Investigation of the Properties of PDLC $s_{N B A 107}$}

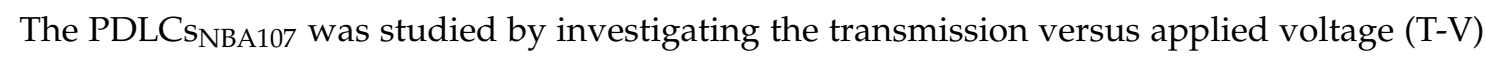

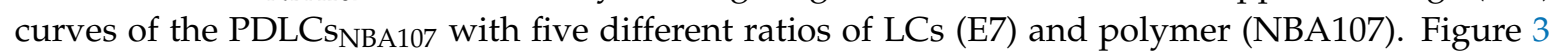
shows the experimental setup for the measurement of the T-V curves. The PDLCs NBA107 $_{\text {cells }}$ (without any surface alignment treatment onto the substrates) with five different ratios of LCs to polymers 
were fabricated using PIPS through UV illumination with a UV intensity of $1.0 \mathrm{~mW} / \mathrm{cm}^{2}$ for $60 \mathrm{~min}$. The reason for selecting this particular UV intensity and illumination duration for fabrication processes will be discussed later. In Figure 3, the probe beam from a He-Ne laser was expanded by using a beam expander, and then passed through an iris. The intensity was reduced using a neutral density filter (NDF). The light was split into two beams by using a beam-splitter cube. One beam was used to measure the transmission of the PDLCs $\mathrm{NBA}_{\mathrm{N} 107}$ cell, whereas the other beam was used to detect the intensity stability of the probed He-Ne laser. The distance between the photo-detector and the PDLC cell for all T-V curve measurements was set at around $30 \mathrm{~cm}$ for the baseline, and the collection angle of the scattering was about $0.8^{\circ}$.

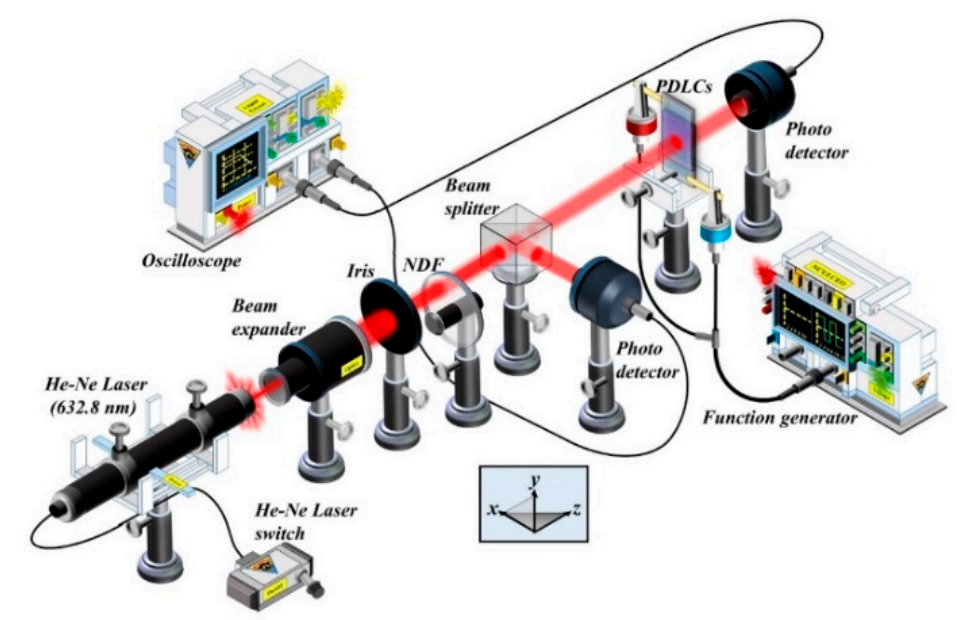

Figure 3. Experimental setup, drawn using Microsoft PowerPoint, for the measurement of transmission versus applied voltage $(\mathrm{T}-\mathrm{V})$ curves of PDLCs $\mathrm{NBA}_{\mathrm{N} 107}$ and PDLCs $\mathrm{SOA65}_{\mathrm{N}}$.

The red, green, blue, orange, and black curves shown in Figure 4 present the T-V curves of

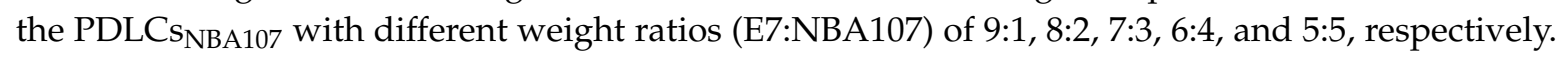
The experimental results of the transmissions shown in Figure 4 are based on the experimental setup

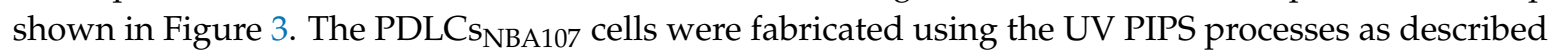
previously. Figure 5a-e present the microscopic images of the PDLCs NBA107 $_{\text {with different weight }}$ ratios (E7:NBA107) of 9:1, 8:2, 7:3, 6:4, and 5:5, respectively, observed under a cross-polarized optical

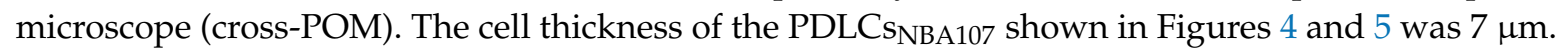

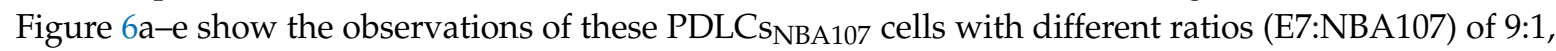
8:2, 7:3, 6:4, and 5:5 without any applied voltage, corresponding to the initial transmissions of the red, green, blue, orange, and black curves shown in Figure 4, respectively. The detailed discussion will be provided in the next paragraph.

In Figure 5a, the concentration of the mixed monomer, NBA107, was too low to generate suitable LC droplets and a continuous polymer matrix to achieve good light-scattering for the

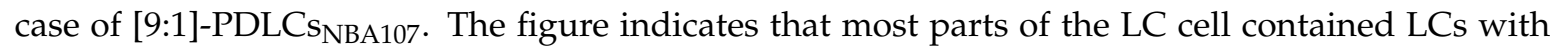
various orientations. The small, polymer-rich areas (white circle in Figure 5a), which were randomly distributed, were formed through the aggregation of polymers during PIPS to cause light scattering [1]. The red curve in Figure 4 shows that the slight light loss/scattering of $13 \%$ (82\% to $69 \%$ ) was caused by the small polymer-rich areas and the large LC domains. For further discussion, the relatively small LC droplets in polymer-rich areas are called LC-dropletsPRA. Some of the sizes of the LC-dropletsPRA were believed to be within the regime $(\sim 0.2-10 \mu \mathrm{m})$ to cause visible light scattering.

With the increase in polymer (NBA107) concentration, Figure $5 b, c$ clearly show that the LC droplets with different sizes were generated via PIPS for the cases of [8:2]-PDLCS NBA107 $_{\text {and }}$

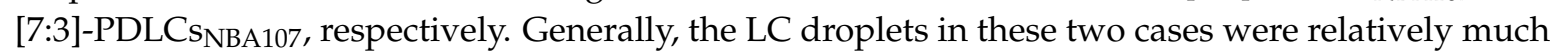

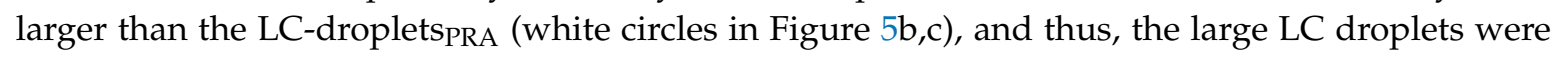

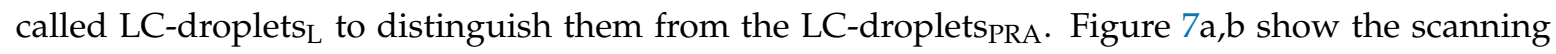




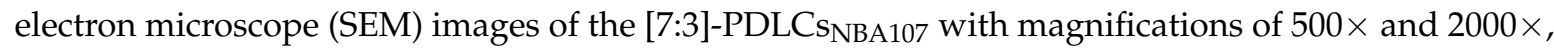
respectively. The large, circle-like area and relatively small black area indicate the size/shape of the

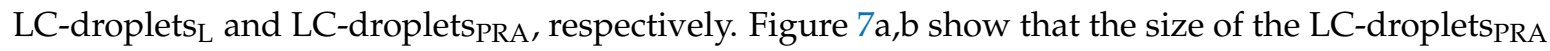
is approximately within $0.2-10 \mu \mathrm{m}$. Clearly, the size of the LC droplets shown in Figure $5 \mathrm{~b}$ is larger than that shown in Figure $5 \mathrm{c}$ because the polymer concentration of the former was lower than that of the latter. However, the sizes of the LC-droplets $\mathrm{L}_{\mathrm{L}}$ shown in Figure $5 \mathrm{~b}, \mathrm{c}$ were both larger than the thicknesses of the LC cell $(7 \mu \mathrm{m})$. This result indicates that the shapes of the LC-droplets $\mathrm{L}_{\mathrm{L}}$ in [8:2]-PDLC $s_{\mathrm{NBA107}}$ and [7:3]-PDLC $\mathrm{s}_{\mathrm{NBA107}}$ were not sphere-like, but rather cylindrical. The formation of the LC-droplets $\mathrm{L}_{\mathrm{L}}$ grew from one substrate to the other during PIPS processes, and thus, the incident light passed through the LC-droplets $\mathrm{L}_{\mathrm{L}}$ areas with only slight light-scattering. Based on Figures 5 and 7 ,

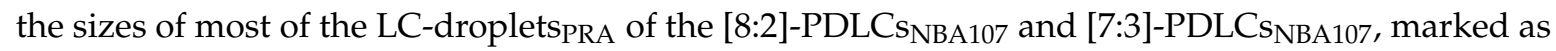
white circles in Figure 5b,c, which are approximately in the order of $0.2-10 \mu \mathrm{m}$, were capable of causing visible light-scattering. Overall, as the transparent LC-droplets $s_{\mathrm{L}}$ areas and scattering polymer-rich area

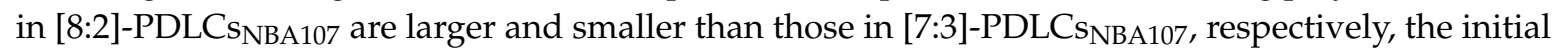
transmission of the former (green curve in Figure 4) is higher than that of the latter (blue curve in Figure 4).

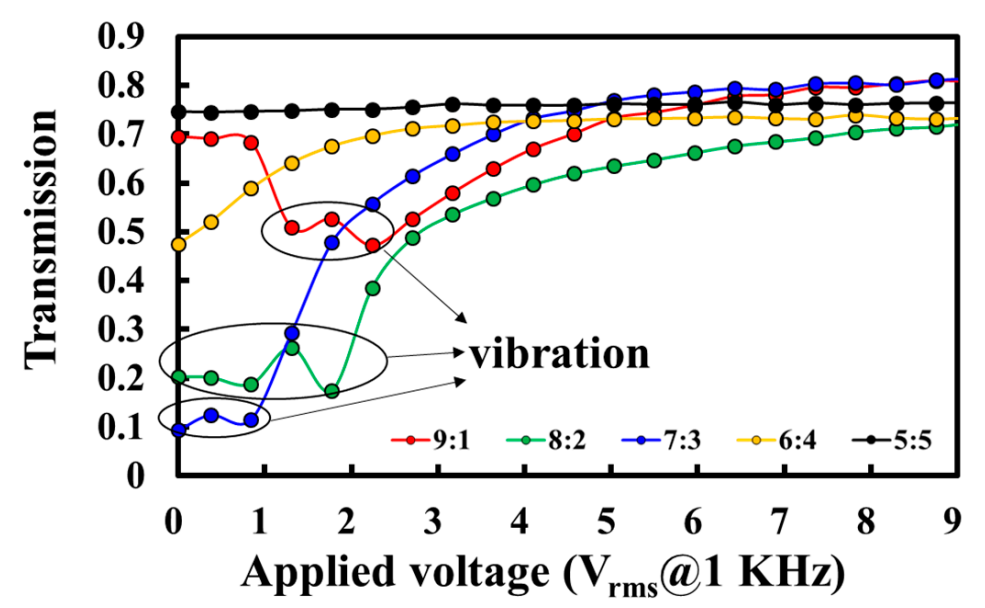

Figure 4. Transmission versus applied voltage $(\mathrm{T}-\mathrm{V})$ curves of PDLC $\mathrm{s}_{\mathrm{NBA} 107}$ with different ratios (E7:NBA107), including the weight ratios of 9:1, 8:2, 7:3, 6:4, and 5:5. The applied electric field is an alternating current $(\mathrm{AC})$ square wave.

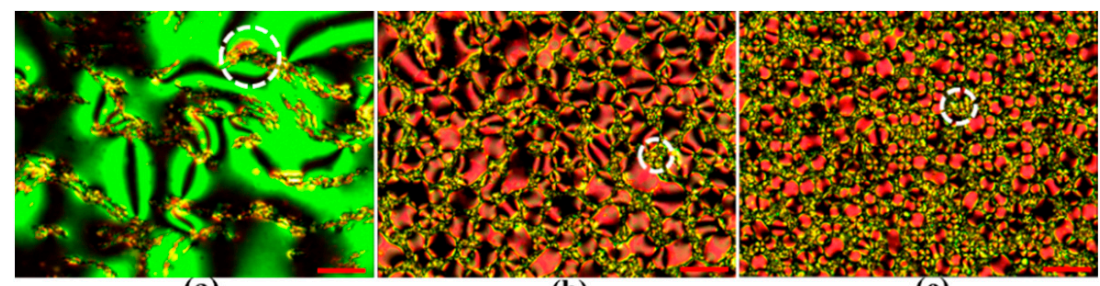

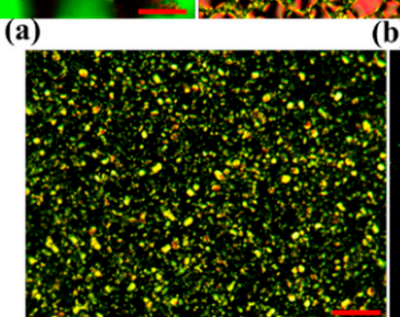

(d)

(b)

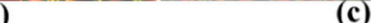

(c)

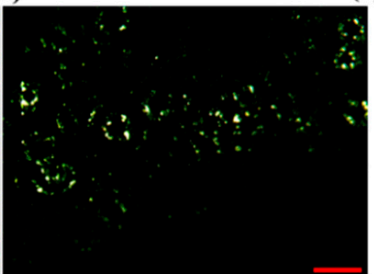

(e)

Figure 5. Images of PDLCs $s_{N B A 107}$ with different ratios (E7:NBA107) of (a) 9:1, (b) 8:2, (c) 7:3, (d) 6:4, and (e) 5:5, observed under a cross-polarized optical microscope (cross-POM). The red scale bars (bottom-right side of each photo) represent a length of approximately $40 \mu \mathrm{m}$. 


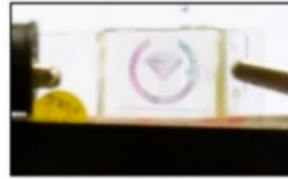

(a)

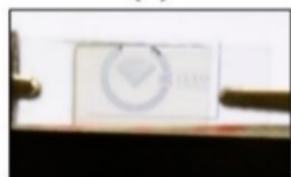

(d)

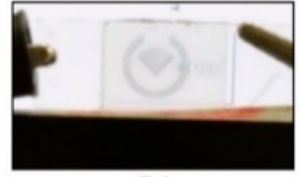

(b)

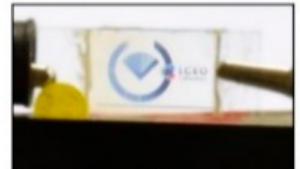

(e)

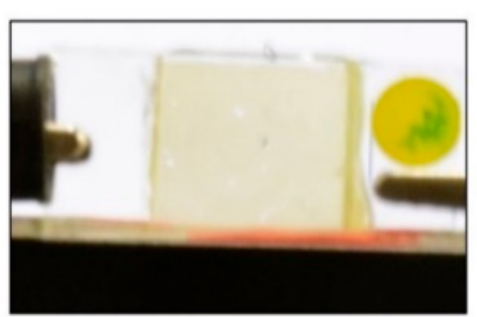

(c)

Figure 6. Photographs of scattering performances of different PDLC $\mathrm{s}_{\mathrm{NBA} 107}$ cells fabricated with different weight ratios of materials (E7:NBA107), including (a) 9:1, (b) 8:2, (c) 7:3, (d) 6:4, and (e) 5:5, at a zero applied-voltage state.

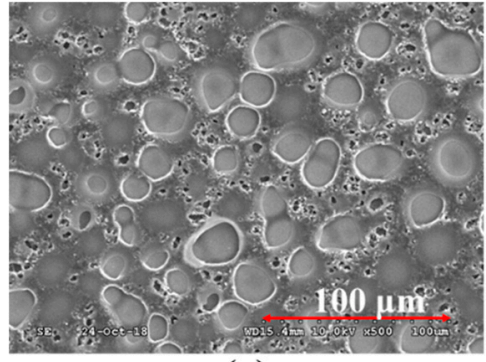

(a)

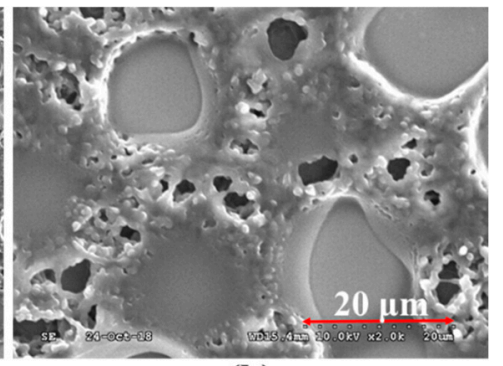

(b)

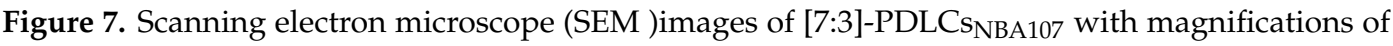
(a) $500 \times$ and (b) $2000 \times$.

By increasing the polymer (NBA107) concentration further, we deduced that the sizes of some LC-droplets ${ }_{\text {PRA }}$ of the [6:4]-PDLC $s_{\text {NBA107 }}$ [Figure $5 \mathrm{~d}$ ] were not in the order of $\sim 0.2-10 \mu \mathrm{m}$ to cause scattering for visible lights. The polarization directions of the incident lights after passing through the non-scattering polymer-rich areas remained almost unchanged because the phase retardation contributed by the LCs in LC-dropletsPRA was limited and were absorbed by the analyzer of the cross-POM. Accordingly, some small black domains, shown in Figure 5d, can be observed. The sizes of some LC-droplets ${ }_{L}$ (light-yellow areas in Figure 5d) are larger than $7 \mu \mathrm{m}$, thereby allowing the incident lights to pass through the LC-droplets $s_{\mathrm{L}}$ areas with slight light scattering. Some LC-droplets PRA $_{\text {LC-droplets }}$, with sizes in the order of $0.2-10 \mu \mathrm{m}$ were the main reason to cause the scattering of visible lights. Overall, the initial transmission of the [6:4]-PDLC NBA107 $_{\text {(orange }}$ curve in Figure 4) is higher than that of the [7:3]-PDLCs ${ }_{\mathrm{NBA107}}$ (blue curve in Figure 4) because some lights can pass through the [6:4]-PDLCs ${ }_{\mathrm{NBA} 107}$ with non-scattering polymer-rich areas and some LC-droplets L $_{\mathrm{L}}$ areas, whose sizes are larger than $7 \mu \mathrm{m}$.

With an increasingly high polymer (NBA107) concentration, the sizes of most LC-dropletsPRA in

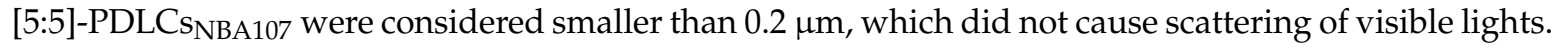
The polarization directions of the incident lights after passing through the non-scattering polymer-rich areas remained almost unchanged. Hence, Figure 5 e shows the observations of an almost black state under cross-POM because most incident lights were absorbed by the analyzer. The LC-droplets ${ }_{\mathrm{L}}$ (light-yellow areas in Figure 5e) with a few micrometers in size can be observed under cross-POM. However, LC-droplets with their size smaller than several hundreds of nanometers were not clearly observed because their sizes were beyond the microscope resolution limit [30]. Accordingly, the initial transmission of the [5:5]-PDLC $s_{\mathrm{NBA} 107}$ was $\sim 75 \%$, which is close to the transmission ( $\sim 82 \%$ ) of an empty cell. The light loss of $7 \%$ was mostly caused by the light scattering resulting from the LC-droplets $\mathrm{L}_{\mathrm{L}}$ areas, the sizes of which were in the order of $0.2-10 \mu \mathrm{m}$. 
Figure 4 shows that the vibrations of the transmissions of the red, green, and blue T-V curves (black circles) occurred when the applied voltages were not high enough. Based on the green and blue T-V curves in Figure 4, we infer that the LCs applied with low external fields in the center of each LC-droplets $\mathrm{L}_{\mathrm{L}}$ / LC-dropletsPRA started to rotate slightly, because the anchoring strength of the polymer surface was relatively weak there [1,2]. A small LC domain formed in the center of each LC droplet, of which the refractive index was different from the surrounding LCs, causing weak light scattering. The cause of the vibration of the red T-V curve in Figure 4 can be understood as being because the applied field induced reorientations of LCs in the central parts of large LC areas and LC-dropletsPRA, of which the refractive indices were different from the adjacent LCs anchored by the polymer matrix to cause light scattering. Beyond the vibrations, the transmissions shown in these curves, except for the black one in Figure 4, increase with an increase of applied voltage because LCs gradually rotate to be perpendicular to the substrates through the application of various applied voltages to reduce refractive index mismatch between LCs and polymers. The increase in the transmission of the [5:5]-PDLCs NBA107 $_{10}$ (black curve in Figure 4) was limited because the light-scattering source, i.e., the LC-droplets $\mathrm{L}_{\mathrm{L}}$ areas in Figure 5 e, was extremely small. Among the curves in Figure 4, the optimized ratio of the PDLCs NBA107 to approach the lowest $\mathrm{V}_{\mathrm{th}}\left(<1 \mathrm{~V}_{\mathrm{rms}}\right)$ and the lowest transmission $(\sim 9.4 \%)$ is $7: 3$.

The selected intensity $\left(1.0 \mathrm{~mW} / \mathrm{cm}^{2}\right)$ of UV light for PIPS in the aforementioned experiments was optimized. The red, green, blue, and yellow curves shown in Figure 8 present the T-V curves of the

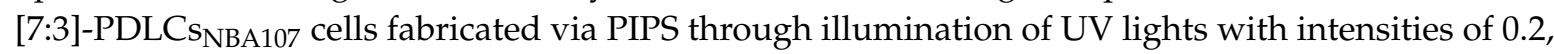
$1.0,4.0$, and $8.0 \mathrm{~mW} / \mathrm{cm}^{2}$, respectively, for $60 \mathrm{~min}$. The cell thickness of the four cells was $7 \mu \mathrm{m}$. In accordance with these experimental results, Table 3 lists the $\mathrm{V}_{\mathrm{th}}$, initial transmission, and saturated transmission of these four [7:3]-PDLC $s_{\mathrm{NBA107}}$ cells. The values of $\mathrm{V}_{\mathrm{op}}$, defined as the applied voltage

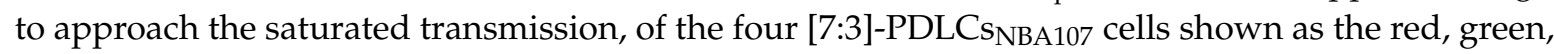
blue, and orange curves in Figure 8 are considered to be approximately below $7.36 \mathrm{~V}_{\mathrm{rms}}$. The saturated transmission remains almost invariant when the applied voltage is higher than $\mathrm{V}_{\mathrm{op}}$.

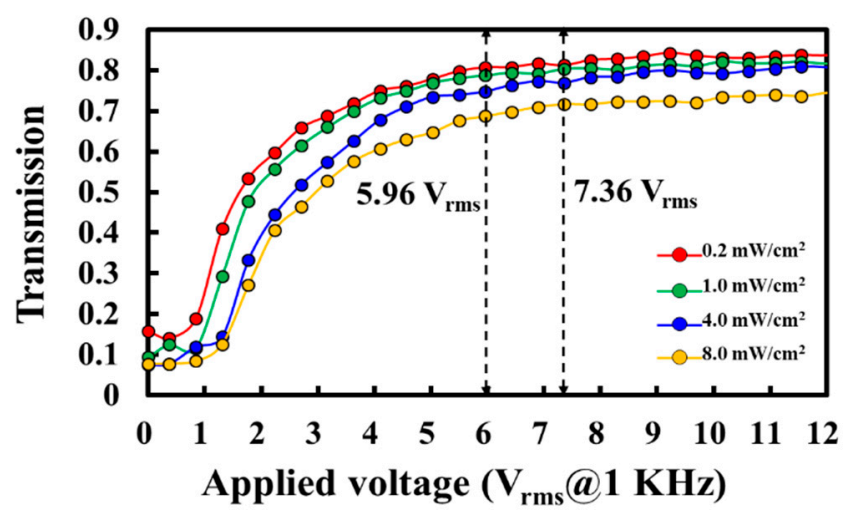

Figure 8. Transmission versus applied voltage (T-V) curves of different [7:3]-PDLCs NBA107 $_{\text {cells }}$ fabricated via polymerization-induced phase separation (PIPS) through the illumination of UV lights with intensities of $0.2,1.0,4.0$, and $8.0 \mathrm{~mW} / \mathrm{cm}^{2}$ for $60 \mathrm{~min}$. The applied electric field is an alternating current $(\mathrm{AC})$ square wave.

Table 3. Threshold voltage $\left(\mathrm{V}_{\mathrm{th}}\right)$, initial transmission, and saturated transmission of different

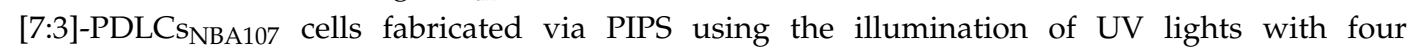
different intensities.

\begin{tabular}{cccc}
\hline UV Light Intensity $\left(\mathbf{m W} / \mathbf{c m}^{\mathbf{2}}\right)$ & $\mathbf{V}_{\text {th }}\left(\mathbf{V}_{\text {rms }}\right)$ & Initial Transmission & Saturated Transmission \\
\hline 0.2 & $<1.0$ & 0.158 & 0.812 \\
1.0 & $<1.0$ & 0.094 & 0.804 \\
4.0 & $<1.5$ & 0.075 & 0.769 \\
8.0 & $<1.5$ & 0.077 & 0.717 \\
\hline
\end{tabular}


Figure 9a-d show the microscopic images of the abovementioned [7:3]-PDLC $s_{\text {NBA107 }}$ cells fabricated via PIPS with UV intensities of $0.2,1.0,4.0$, and $8.0 \mathrm{~mW} / \mathrm{cm}^{2}$, respectively, observed under a cross-POM. In Figure 8, the initial transmission of the [7:3]-PDLC s $_{\mathrm{NBA} 107}$ cells applied with an AC voltage of approximately $7.36 \mathrm{~V}_{\mathrm{rms}}$ and the $\mathrm{V}_{\text {th }}$ decreased and increased with the increase of UV light intensity, respectively. Based on the images shown in Figure 9, this result is reasonable

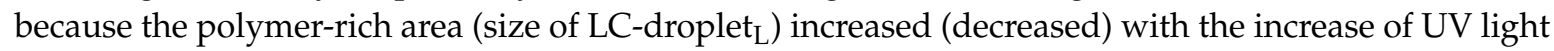
intensity $[1,2]$. Moreover, a large (small) LC-droplets ${ }_{\mathrm{L}}$ (polymer-rich area) suggests that less incident lights can be scattered, resulting in an increase in initial transmission.

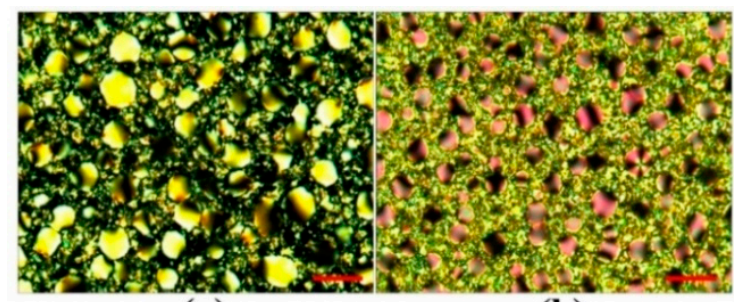

(a)

(b)

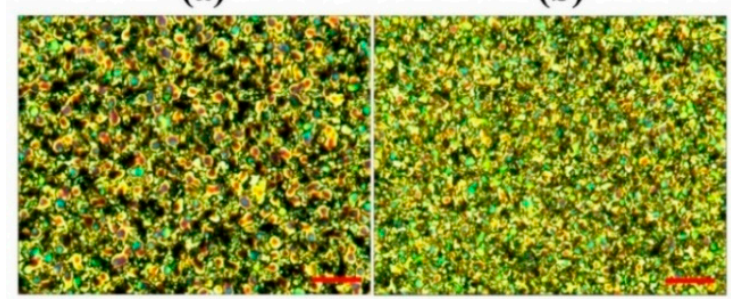

(c)

(d)

Figure 9. Microscopic images of the [7:3]-PDLCs ${ }_{\mathrm{NBA} 107}$ cells fabricated via PIPS using the illumination of UV lights with intensities of (a) 0.2 , (b) 1.0 , (c) 4.0 , and (d) $8.0 \mathrm{~mW} / \mathrm{cm}^{2}$ observed under a cross-POM. The red scale bars (bottom-right side of each photo) represent a length of approximately $40 \mu \mathrm{m}$.

To approach low $\mathrm{V}_{\text {th }}$, among all curves in Figure 8, and based on Table 3, the $\mathrm{V}_{\text {th }}\left(<1 \mathrm{~V}_{\text {rms }}\right)$ of the [7:3]-PDLC $s_{\mathrm{NBA} 107}$ of the red and green curves were the lowest. Given that the latter had lower initial transmission than the former, the PIPS of UV illumination with the intensity of $1.0 \mathrm{~mW} / \mathrm{cm}^{2}$ was selected to be the optimized fabrication condition. The $\mathrm{V}_{\mathrm{op}}\left(\sim 5.96 \mathrm{~V}_{\mathrm{rms}}\right)$ of the [7:3]-PDLC $\mathrm{s}_{\mathrm{NBA107}}$ of the green curve was relatively low. Moreover, the contrast ratio of [7:3]-PDLC s $_{\text {NBA107 }}$ fabricated following the optimized processes was high enough for real applications, such as electrically switchable windows, light shutters, and e-papers [1,2]. Regarding the response time of the optimized [7:3]-PDLCs NBA107, $_{\text {, }}$ its rise (decay) time was measured to be about 1.5 (193) ms. Compared with other PDLCs, the cause of such low $\mathrm{V}_{\text {th }}$ and relatively long decay time can be understood because the [7:3]-PDLCs NBA107 possesses relatively weak surface-anchoring [1,20,31-33]. A method to shorten the decay time in

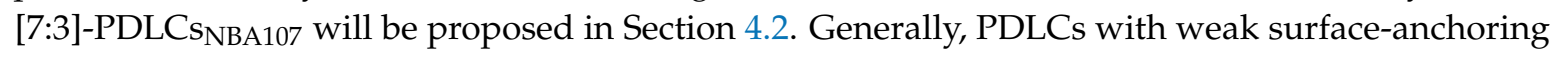
possess low $\mathrm{V}_{\text {th }}$, and the relationship between the $\mathrm{V}_{\text {th }}$ and LC droplet size of PDLCs with weak surface-anchoring can be described using Equation (1) [1]:

$$
E_{t h}=\frac{V_{\text {th }}}{d}=\left(\frac{a_{\text {surface }} W}{a_{\text {electric }} \Delta \varepsilon}\right)^{\frac{1}{2}} \frac{1}{\sqrt{D}} \propto \frac{1}{\sqrt{D}}
$$

where $E_{t h}, V_{t h}, d, W, \Delta \varepsilon$, and $D$ represent the threshold field, threshold voltage, cell thickness (gap), anchoring strength of droplet surface, LC dielectric anisotropy, and droplet size (diameter), respectively. $a_{\text {surface }}$ and $a_{\text {electric }}$ are constants. Equation (1) represents the fact that the $V_{\text {th }}$ decreases with the increase [decrease] of UV light intensity [LC droplet size, D] as shown in Figure 8. To further investigate the surface anchoring conditions of the [7:3]-PDLCs $s_{\mathrm{NBA} 107}$ onto the $\mathrm{V}_{\text {th }}$ of PDLCs, another famous polymer of Norland Products Inc., NOA65, was selected for comparison with NBA107. We fabricated [7:3]-PDLCs NBA107 $_{\text {, [7:3]-PDLC }}$ sOA65 $_{\text {and [5:5]-PDLC }}$ NOA65 $_{\text {by }}$ using the PIPS of UV illumination 
$\left(1.0 \mathrm{~mW} / \mathrm{cm}^{2}\right)$ for $60 \mathrm{~min}$. The cell thickness used in the [7:3]-PDLC $\mathrm{s}_{\mathrm{NBA} 107}$ and [7:3]-PDLC $\mathrm{s}_{\mathrm{NOA} 65}$ cells was $7 \mu \mathrm{m}$ Figure 10 illustrates the measurements of the T-V curves of the [7:3]-PDLCs NBA107, $_{\text {, }}$

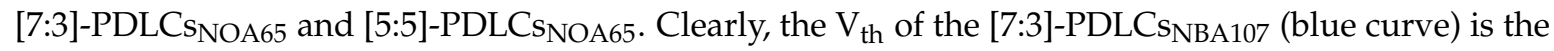

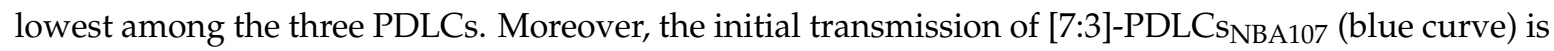
slightly lower than that of the [7:3]-PDLC $s_{\text {NOA65 }}$ (orange curve). Decreasing concentration of NOA65 to increase $\mathrm{LC}$ droplet size can further decrease $\mathrm{V}_{\text {th }}$ (orange curve), but the initial transmission might increase to decrease the contrast ratio, which can refer to Figure 4 [1,2]. It is well-known that the surface anchoring of NOA65 is weak [1]. Thus, based on Figure 10, the surface anchoring of the NBA107 is believed to be weaker than or equal to that of NOA65 [1,33]. We deduce that the reason for

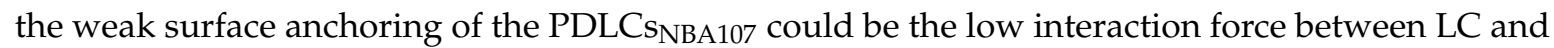
polymer molecules [20].

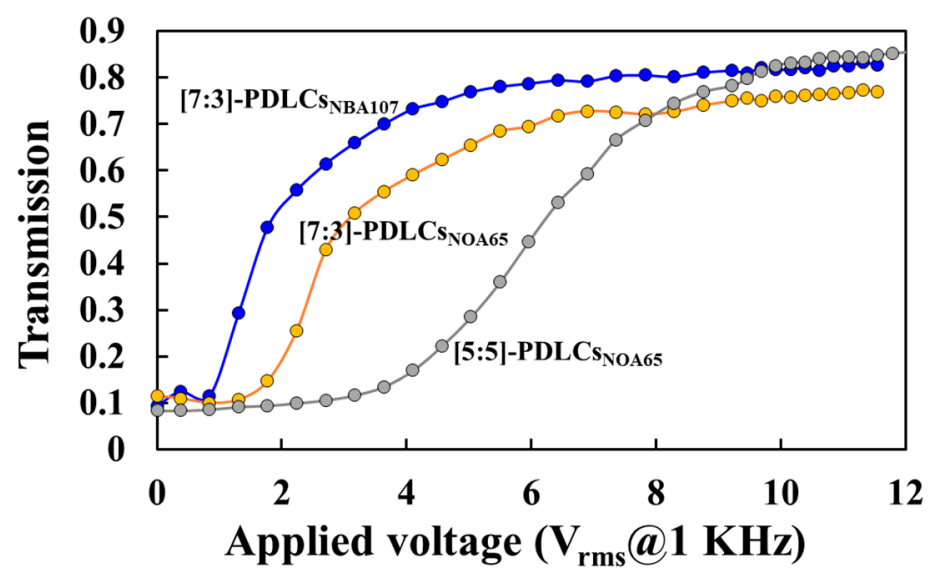

Figure 10. Transmission versus applied voltage (T-V) curves of the [7:3]-PDLCs NBA107, $_{\text {[7:3]-PDLCS }}$ NOA65 and [5:5]-PDLC NOA65. $_{\text {. }}$

\subsection{Electrically Switchable Dual-Polarization Scattering Shutter}

The experimental setup for the following experiments was identical with that shown in Figure 3, except for the addition of the polarizer, which was placed between the NDF and the beam splitter. The measurement of the T-V curve of the PSMLS was achieved by rotating the transmission axis

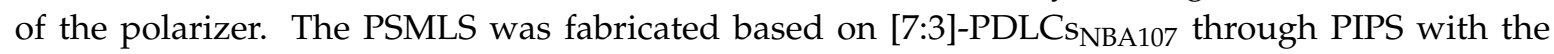
optimized fabrication processes (UV light illumination with intensity of $1.0 \mathrm{~mW} / \mathrm{cm}^{2}$ for $60 \mathrm{~min}$ ). The scattering performances of the PSMLS when various electric potentials were applied onto the blue and light-yellow interdigital electrode stripes (Figure 2a) are discussed in the following paragraph.

The orange and blue curves in Figure 11a show the T-V curves of the PSMLS when the polarization directions of the incident lights were parallel and perpendicular to the direction of the interdigital electrode stripes, respectively. The experimental results show that the lights with a polarization direction parallel to the direction of the interdigital electrode stripes can pass through the PSMLS, whereas the lights with a polarization direction perpendicular to the interdigital electrode stripes are scattered. The $\mathrm{V}_{\text {th }}$ of the fabricated PSMLS was lower than $2 \mathrm{~V}_{\text {rms }}$ because of the use of [7:3]-PDLC $\mathrm{S}_{\mathrm{NBA107}}$, which was fabricated via optimized fabrication processes. Figure $11 \mathrm{~b}$ shows the observation of the PSMLS in the initial scattering condition (without any application of an external voltage). A linear polarizer was placed between the PSMLS and camera. Figure 11c,d shows the experimental results, where the PSMLS was transparent (opaque) when the polarization direction of the incident lights was parallel (perpendicular) to the direction of the interdigital electrode stripes (when applied voltage is $18.5 \mathrm{~V}_{\mathrm{rms}}$ ). However, based on the orange curve in Figure 11a, the $\mathrm{V}_{\mathrm{op}}$ of the PSMLS was larger than $22 \mathrm{~V}_{\mathrm{rms}}$, which is higher than the original $\mathrm{V}_{\mathrm{op}}\left(\sim 5.96 \mathrm{~V}_{\mathrm{rms}}\right)$ shown in Figure 8 . The reason for this low original $\mathrm{V}_{\text {op }}$ (Figure 8) is that the applied field strength onto a common PDLC cell, assembled by using two ITO-coated glass substrates, is uniform across the bulk of the PDLC 
cell. This result indicates that the LCs in all LC droplets in the bulk of the cell orient at the same time through the application of an external field. By contrast, the applied field strength is reduced gradually from the bottom interdigital electrode to the top substrate in the PSMLS (Figure 2a). When specific suitable electric potentials are applied onto the blue and light-yellow interdigital electrode stripes (Figure 2a), the field strength can rotate the LCs with their director projection on the $\pm x$-axis in LC droplets near the bottom interdigital electrodes (Figure 2a) to be perpendicular to the direction of the interdigital electrode stripes; however, the field strength near the top substrate is not high enough to rotate the LCs in LC droplets. Hence, the applied voltage must be increased further to rotate the LCs in all LC droplets in the bulk of PSMLS. Moreover, the blue curve (Figure 11a) shows that the transmission of the PSMLS applied with approximately $16 \mathrm{~V}_{\text {rms }}$ for the case of incident lights with the polarization direction perpendicular to the direction of the interdigital electrode stripes was higher than the initial transmission. This result indicates that the scattering strength is stronger when the LCs in LC droplets point to random directions than that when the LCs in LC droplets are rotated to be the configuration of Figure $2 \mathrm{a}$ via the applied voltage $\left(16 \mathrm{~V}_{\mathrm{rms}}\right)$. The cause can be understood because the corresponding refractive index mismatches were different.

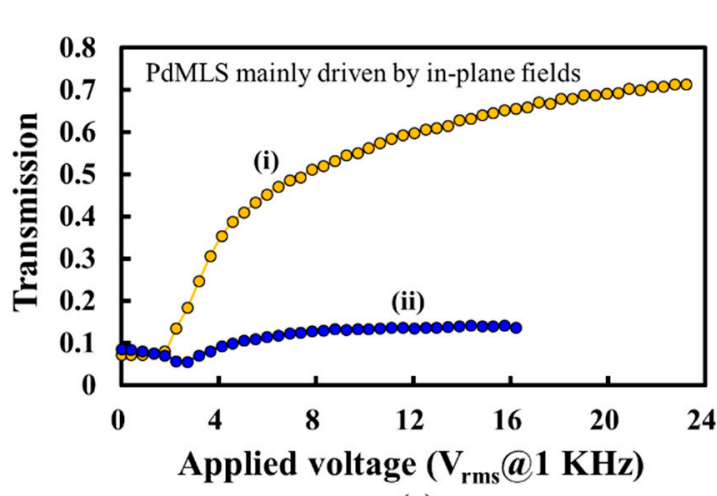

(a)

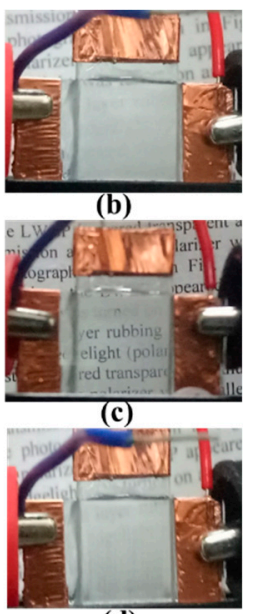

(d)

Figure 11. (a) T-V curves of PSMLS when the polarization directions of the incident lights are (i) parallel (orange) and (ii) perpendicular (blue) to the direction of the interdigital electrode stripes. (b) Photo of the PSMLS in the initial scattering condition (without any application of field). Photos of (c) transparent and (d) opaque PSMLS when the polarization direction of the incident lights is parallel and perpendicular to the direction of the interdigital electrode stripes (when the applied voltage is $18.5 \mathrm{~V}_{\text {rms }}$ ), respectively. The applied electric field is an AC square wave.

The scattering performances of the PSMLS driven by the applied vertical fields, as shown in Figure $2 b$, are discussed in the following paragraph. Figure 12a shows the T-V curve when the polarization direction of the incident lights is perpendicular to the interdigital electrode stripes. The T-V curve in Figure 11a should be similar to that in Figure 8 because both curves were measured from the PDLC cells driven by vertical fields. However, the $V_{\text {op }}$ and $V_{\text {th }}$ shown in Figure 12a are higher than those shown in Figure 8 because of the dead zones with slight fringe fields (Figure $2 b$ ) in the PSMLS. The highest transmission in Figure 12a was also lower than that in Figure 8, which was elucidated in Section 2. Briefly, on the basis of Figure 2b, the fringing electric fields close to the electrode stripe edges were not completely perpendicular to the substrates, so light-scattering occurred there because of a small refractive index mismatch between LCs and polymers to reduce the transmission. A small amount of LCs in LC droplets close to the dead zones (orange region in Figure 2b), which cannot be electrically oriented, also caused the reduction of transmittance. Moreover, the $V_{\text {op }}$ in Figure 12a is higher than that in Figure 8, which is reasonable because a high applied voltage was required to reorient LCs closer to the edges of the electrode stripes. The transmission versus linear polarization 
angle (LPA) curve of the PSMLS through the application of an applied voltage ( 13.9 $\left.\mathrm{V}_{\text {rms }}\right)$ was measured to investigate the polarization sensitivity of the PSMLS driven by vertical fields, as shown in Figure 12b. The LPA is defined as the angle between the absorption axis of the polarizer and the direction of the interdigital electrode stripes. On the basis of Figure $2 \mathrm{~b}$, when the LPA is $0^{\circ} / 180^{\circ}\left(90^{\circ}\right)$, i.e., the incident light with the polarization direction is perpendicular (parallel) to the direction of the interdigital electrode stripe, the incident lights encounter $n_{\mathrm{e}} / n_{\text {eff }}\left(n_{\mathrm{o}}\right)$ of LCs in the LC droplets close to the interdigital electrode stripe edges. As the refractive index of the polymer (NBA107) becomes closer to the $n_{\mathrm{o}}$ of nematic LC (E7), the incident lights with the polarization direction perpendicular (parallel) to interdigital electrode stripes encounter a small $(\sim 0)$ refractive index mismatch between polymer and LCs close to the interdigital electrode stripe edges. The incident lights with the polarization direction perpendicular to the interdigital electrode stripes should be slightly scattered. The transmission when the LPA is $0^{\circ} / 180^{\circ}$ is slightly lower than that when the LPA is $90^{\circ}$, as shown in Figure $12 \mathrm{~b}$. We infer that the slightly low transmission (LPA of $0^{\circ} / 180^{\circ}$ ) results from the slight mismatch of refractive indices between the LCs and polymer (NBA107) close to the interdigital electrode stripe edges. Figure 12c,d show the images of the PSMLS when the LPAs are $0^{\circ} / 180^{\circ}$ and $90^{\circ}$, respectively. A linear polarizer for the setup of Figure 12c,d was placed between the PSMLS and camera. The clarity of the words (background) in Figure 12c,d is approximately the same.

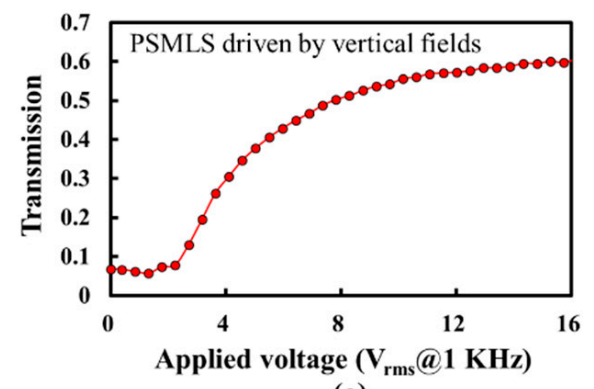

(a)

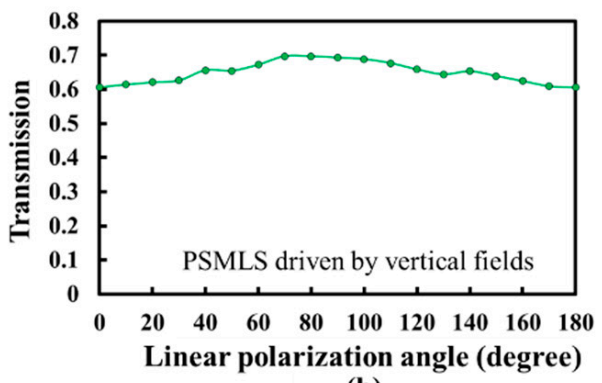

(b)

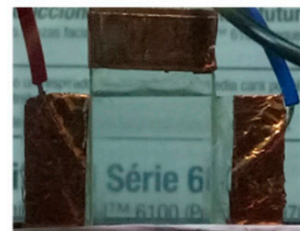

(c)

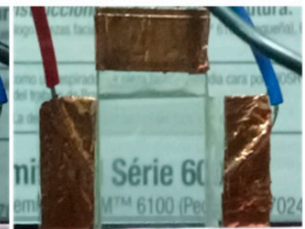

(d)

Figure 12. (a) T-V curve of the PSMLS for the incident lights with their polarization direction perpendicular to the direction of the interdigital electrode stripe. (b) Transmission versus linear polarization angle (LPA) curve of the PSMLS driven by vertical fields. The observations of the PSMLS applied with a vertical field of about $13.9 \mathrm{~V}_{\text {rms }}$ when the LPA was (c) $0^{\circ}$ and (d) $90^{\circ}$. The applied electric field is an AC square wave.

The [7:3]-PDLCs NBA107 $_{\text {can realize low }} \mathrm{V}_{\text {th }}$ and $\mathrm{V}_{\text {op }}$ due to its weak surface-anchoring, but the cost

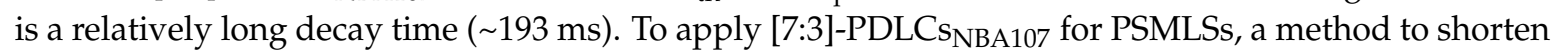
its decay time is elucidated as follows. Based on the results in Figure $11 \mathrm{c}, \mathrm{d}$, we proposed the method to approach a fast switch between a polarization-selective scattering state and polarization-independent transparent state. Figure 13a shows that when the PSMLS is applied with a vertical field, the input $x$-LPLs can pass through the PSMLS (Figure 12c). The potentials of $\mathrm{V}_{\mathrm{a}}, \mathrm{V}_{\mathrm{b}}$, and $\mathrm{V}_{\mathrm{c}}$ to obtain the transparent state, as shown in Figure $13 a$, are $V_{o p}, V_{o p}$, and 0 , respectively. Figure $13 b$ shows that to obtain the light scattering of $x$-LPLs (Figure $11 \mathrm{~d}$ ), the potentials of $\mathrm{V}_{\mathrm{a}}, \mathrm{V}_{\mathrm{b}}$, and $\mathrm{V}_{\mathrm{c}}$ of the PSMLS are $0, \mathrm{~V}_{\mathrm{op}}$, and open circuit potential (floating), respectively. Because the switch from transparent to scattering states of $x$-LPLs in PSMLS is driven by the applied electric fields rather than the weak surface anchoring in each LC droplet, the switch time can be further shortened $[1,22,23]$. By contrast, the required time of switch from transparent to scattering states in a common PDLC device depends only 
on surface anchoring in each LC droplet; therefore, its switch time is relatively long [1,2]. To simplify the design to approach this method, the interdigital electrode stripes can be replaced by using a configuration consisting of grid electrodes located on top of a common electrode [22,23].

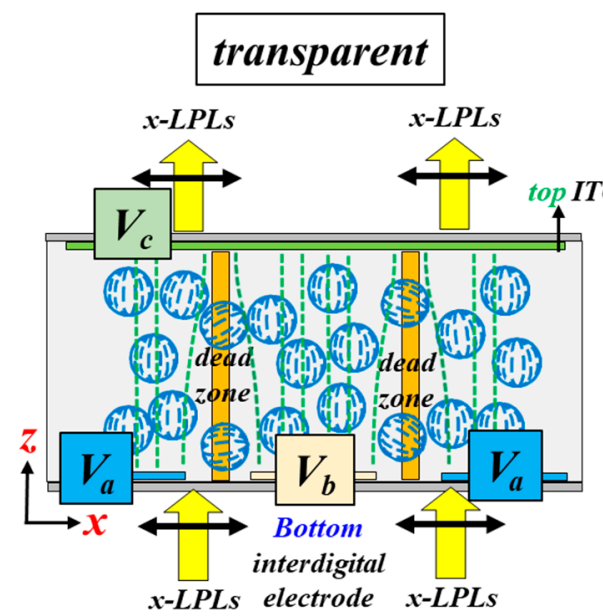

(a)

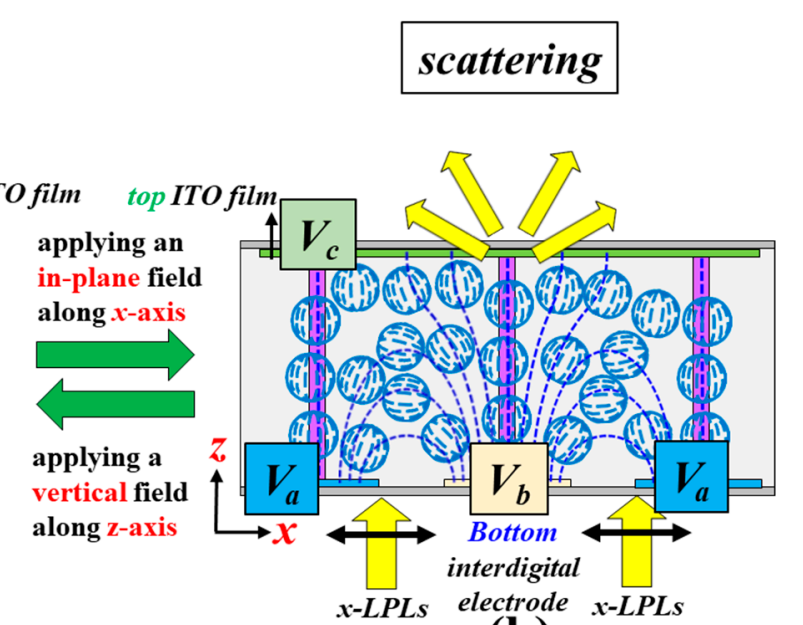

(b)

Figure 13. (a) Schematic drawings of a PSMLS when the potentials of $\mathrm{Va}, \mathrm{V}_{\mathrm{b}}$, and $\mathrm{V}_{\mathrm{c}}$ are $\mathrm{V}_{\mathrm{op}}, \mathrm{V}_{\mathrm{op}}$, and 0 , respectively, enabling the input $x$-LPLs to pass through the PSMLS. (b) Schematic drawings of a PSMLS when the potentials of $\mathrm{Va}, \mathrm{V}_{\mathrm{b}}$, and $\mathrm{V}_{\mathrm{c}}$ are $0, \mathrm{~V}_{\mathrm{op}}$, and open circuit potential (floating), respectively, to obtain the light scattering of $x$-LPLs.

\section{Conclusions}

Low-threshold-voltage, low-operation-voltage, and electrically switchable PSMLSs using

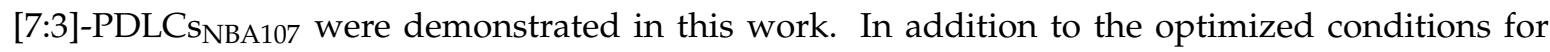
fabrication processes, the electro-optical properties, including scattering performance, $V_{\text {th }}$, initial transmission, surface anchoring, and droplet size, of the [7:3]-PDLC $s_{\text {NBA107 }}$ were investigated. The full

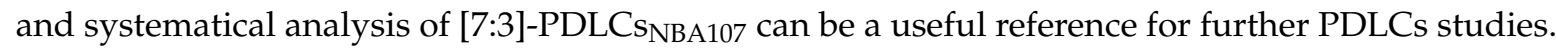
The relationship between the $\mathrm{V}_{\text {th }}$ and LC droplet size of PDLCs based on surface anchoring was discussed. The $\mathrm{V}_{\text {th }}$ and $\mathrm{V}_{\text {op }}$ of the $7 \mu \mathrm{m}$-thick [7:3]-PDLCs $\mathrm{s}_{\text {NBA107 }}$ cells produced via optimized fabrication processes are lower than 1 and $6 \mathrm{~V}_{\text {rms }}$, respectively. Moreover, the contrast ratio of

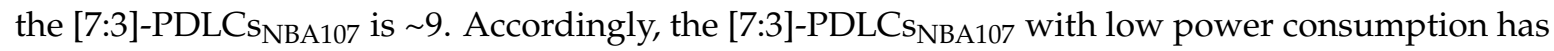
considerable potential to be applied in the various areas of optics [1-12]. The scattering performances of the PSMLS mainly driven by in-plane and/or vertical fields with low $V_{\text {th }}$ were also demonstrated. The PSMLS mainly driven by the in-plane field can scatter lights with the polarization direction perpendicular to the direction of the interdigital electrode stripes, whereas the scattering of the PSMLS driven by the vertical field is insensitive to the polarization direction of incident lights. Accordingly, the PSMLS can be adopted to be an electrically switchable PSMLS for linearly polarized or unpolarized lights for projection or 3D display applications. The weak surface anchoring of [7:3]-PDLCs NBA107 can realize low $V_{\text {th }}$ and $V_{\text {op }}$, but the cost is a long decay time. When [7:3]-PDLCs $s_{\text {NBA107 }}$ is applied for PSMLSs, to reduce decay time, the switch from transparent to scattering states in PSMLS can be driven by the applied electric fields rather than the weak surface anchoring of the adopted polymer. Hence, the fast switch between a polarization-selective scattering state (Figure 11d) and polarization-independent transparent state (Figure 12c) in the PSMLS is feasible with a suitable electrode design [22-25]. Also, the response time of a switch between polarization-independent light scattering and transparency based on PDLCs can be reduced according to the similar method, with two substrates having orthogonally interdigital electrode stripes [34]. 
Author Contributions: C.-K.L. and K.-T.C. wrote the manuscript and proposed the theoretical analysis. Z.-Y.L. fabricated the LC cells and performed the experiments. Z.-Y.L., C.-K.L., K.-T.C. and T.-H.Y. analyzed the experimental results. C.-K.L. and C.-Y.T. completed the SEM measurement. K.-T.C. and C.-K.L. conceived the idea. K.-T.C. supervised the study. All authors reviewed the manuscript.

Funding: This research was financially supported by the Ministry of Science and Technology (MOST) of Taiwan under Grant No. MOST 106-2112-M-008-002-MY3.

Acknowledgments: We deeply appreciate Chao-Yi Tai and Chun-Yu Lin for their help on the SEM measurement. We also sincerely thank the reviewers for their valuable comments and great suggestions.

Conflicts of Interest: The authors declare no conflict of interest.

\section{References}

1. Wu, S.T.; Yang, D.K. Fundamentals of Liquid Crystal Devices; Wiley: Chichester, UK, 2006.

2. Coates, D. Polymer-dispersed liquid crystals. J. Mater. Chem. 1995, 5, 2063-2072. [CrossRef]

3. Doane, J.W.; Vaz, N.A.; Wu, B.G.; Žumer, S. Field controlled light scattering from nematic microdroplets. Appl. Phys. Lett. 1986, 48, 269-271. [CrossRef]

4. Sharma, V.; Kumar, P.; Sharma, A.; Raina, K.K. Droplet configuration control with orange azo dichroic dye in polymer dispersed liquid crystal for advanced electro-optic characteristics. J. Mol. Liq. 2017, 233, 122-130. [CrossRef]

5. Park, M.Y.; Lee, S.Y.; Lee, B.T.; Choi, H.J. Enhancement of the perceived image quality of a 2D/3D convertible directional-backlight unit system using a double-slit barrier array and an active diffuser. Appl. Opt. 2016, 54, 2832-2837. [CrossRef] [PubMed]

6. Wu, S.T.; Fuh, A.Y.G. Two-Dimensional Diffraction Grating Based on Polymer-Dispersed Liquid Crystals. Jpn. J. Appl. Phys. 2004, 43, 7077-7082. [CrossRef]

7. Fuh, A.F.G.; Chen, C.C.; Liu, C.K.; Cheng, K.T. Polarizer-free, electrically switchable and optically rewritable displays based on dye-doped polymer-dispersed liquid crystals. Opt. Express 2009, 17, 7088-7094. [CrossRef] [PubMed]

8. Fukuda, Y.; Tomita, Y. Spatial Frequency Responses of Anisotropic Refractive Index Gratings Formed in Holographic Polymer Dispersed Liquid Crystals. Materials 2016, 9, 188. [CrossRef] [PubMed]

9. Drevenšek-Olenik, I.; Urbančič, I.; Čopič, M.; Sousa, M.E.; Crawford, G.P. In-Plane Switching of Holographic Polymer-Dispersed Liquid Crystal Transmission Gratings. Mol. Cryst. Liq. Cryst. 2008, 495, 177-185. [CrossRef]

10. Drevenšek-Olenik, I.; ČopičM, M.; Sousa, E.; Crawford, G.P. Optical retardation of in-plane switched polymer dispersed liquid crystals. J. Appl. Phys. 2006, 100, 033515. [CrossRef]

11. Available online: http://www.polytron.com.tw (accessed on 4 July 2018).

12. West, J.; Golemme, A.; Doane, J.W. Method of Controlling Microdroplet Growth in Polymeric Dispersed Liquid Crystal. US4673255A, 16 June 1987.

13. Kim, I.I.; McArthur, B.; Korevaar, E. Comparison of laser beam propagation at $785 \mathrm{~nm}$ and $1550 \mathrm{~nm}$ in fog and haze for optical wireless communications. Proc. SPIE 2001, 4214, $26-37$.

14. Available online: https:/ / www.norlandprod.com/adhesiveindex2.html\#special (accessed on 4 July 2018).

15. Wu, S.T.; Fuh, A.Y.G. Lasing in Photonic Crystals based on Dye-Doped Holographic Polymer-Dispersed Liquid Crystal Reflection Gratings. Jpn. J. Appl. Phys. 2005, 44, 977-980. [CrossRef]

16. Bunning, T.J.; Natarajan, L.V.; Tondiglia, V.P.; Sutherland, R.L. Holographic polymer-dispersed liquid crystals (H-PDLCs). Annu. Rev. Mater. Sci. 2000, 30, 83-115. [CrossRef]

17. Natarajan, L.V.; Shepherd, C.K.; Brandelik, D.M.; Sutherland, R.L.; Chandra, S.; Tondiglia, V.P.; Tomlin, D.; Bunning, T.J. Switchable Holographic Polymer-Dispersed Liquid Crystal Reflection Gratings Based on Thiol-Ene Photopolymerization. Chem. Mater. 2003, 15, 2477-2484. [CrossRef]

18. Hsu, C.C.; Chen, Y.X.; Li, H.W.; Hsu, J.S. Low switching voltage ZnO quantum dots doped polymer-dispersed liquid crystal film. Opt. Express 2016, 24, 7063-7068. [CrossRef] [PubMed]

19. Chan, C.H.; Wu, T.Y.; Yen, M.H.; Lin, C.E.; Cheng, K.T.; Chen, C.C. Low power consumption and high-contrast light scattering based on polymer-dispersed liquid crystals doped with silver-coated polystyrene microspheres. Opt. Express 2016, 24, 29963-29971. [CrossRef] [PubMed] 
20. Silva, M.C.; Sotomayora, J.; Figueirinhas, J. Effect of an additive on the permanent memory effect of polymer dispersed liquid crystal films. J. Chem. Technol. Biotechnol. 2015, 90, 1565-1569. [CrossRef]

21. Manda, R.; Pagidi, S.; Bhattacharyya, S.S.; Park, C.K.; Lim, Y.J.; Gwag, J.S.; Lee, S.H. Fast response and transparent optically isotropic liquid crystal diffraction grating. Opt. Express 2017, 25, 24033-24043. [CrossRef] [PubMed]

22. Baek, J.I.; Kim, K.H.; Kim, J.C.; Yoon, T.H.; Woo, H.S.; Shin, S.T.; Souk, J.H. Fast In-Plane Switching of a Liquid Crystal Cell Triggered by a Vertical Electric Field. Jpn. J. Appl. Phys. 2009, 48, 104505. [CrossRef]

23. Song, D.H.; Kim, J.W.; Kim, K.H.; Rho, S.J.; Lee, H.; Kim, H.; Yoon, T.H. Ultrafast switching of randomly-aligned nematic liquid crystals. Opt. Express 2012, 20, 11659-11664. [CrossRef]

24. Lim, Y.J.; Kim, H.J.; Chae, Y.C.; Murali, G.; Lee, J.H.; Mun, B.J.; Gwon, D.Y.; Lee, G.D.; Lee, S.H. Fast Switching and Low Operating Vertical Alignment Liquid Crystal Display with 3-D Polymer Network for Flexible Display. IEEE Trans. Electron Devices 2017, 64, 1083-1087. [CrossRef]

25. Gwag, J.S.; Lee, Y.J.; Kim, M.E.; Kim, J.H.; Kim, J.C.; Yoon, T.H. Viewing angle control mode using nematic bistability. Opt. Express 2008, 16, 2663-2669. [CrossRef] [PubMed]

26. Guo, S.M.; Liang, X.; Zhang, C.H.; Chen, M.; Shen, C.; Zhang, L.Y.; Yuan, X.; He, B.F.; Yang, H. Preparation of a Thermally Light-Transmittance-Controllable Film from a Coexistent System of Polymer-Dispersed and Polymer-Stabilized Liquid Crystals. ACS Appl. Mater. Interfaces 2017, 9, 2942-2947. [CrossRef] [PubMed]

27. Liang, X.; Guo, C.S.; Chen, M.; Guo, S.; Zhang, L.; Li, F.; Guo, S.; Yang, H. A roll-to-roll process for multi-responsive soft-matter composite films containing $\mathrm{Cs}_{\mathrm{x}} \mathrm{WO}_{3}$ nanorods for energy-efficient smart window applications. Nanoscale Horiz. 2017, 2, 319-325. [CrossRef]

28. Liang, X.; Guo, S.; Chen, M.; Li, C.Y.; Wang, Q.; Zou, C.; Zhang, G.H.; Zhang, L.Y.; Guo, S.J.; Yang, H. A temperature and electric field-responsive flexible smart film with full broadband optical modulation. Mater. Horiz. 2017, 4, 878-884. [CrossRef]

29. Chen, M.; Wang, W.; Liang, X.; Gong, S.; Liu, J.; Wang, Q.; Guo, S.J.; Yang, H. Sulfur/Oxygen Codoped Porous Hard Carbon Microspheres for High-Performance Potassium-Ion Batteries. Adv. Energy Mater. 2018, 8, 1800171. [CrossRef]

30. Hecht, E. Optics; Addison Wesley: San Francisco, CA, USA, 2002.

31. Nehring, J.; Kmetz, A.R.; Scheffer, T.J. Analysis of weak-boundary-coupling effects in liquid-crystal. J. Appl. Phys. 1976, 47, 850-857. [CrossRef]

32. Liu, C.K.; Cheng, K.T. Enhancement of surface anchoring energy in low power consumption transflective liquid crystal displays with three display modes. Opt. Commun. 2018, 427, 354-362. [CrossRef]

33. Nie, X.Y.; Lu, R.B.; Xianyu, H.Q.; Wu, T.X.; Wu, S.T. Anchoring energy and cell gap effects on liquid crystal response time. J. Appl. Phys. 2007, 101, 103110. [CrossRef]

34. Choi, T.H.; Kim, J.W.; Yoon, T.H. Fast in-plane switching of negative liquid crystals using crossed patterned electrodes. Jpn. J. Appl. Phys. 2014, 53, 081701. [CrossRef] 